\title{
Dimensions of the parent-child relationship: effects on substance use \\ in adolescence and adulthood
}

Hei Wan Mak ${ }^{\mathrm{a}}(\mathrm{MSc})$, Maria Iacovou ${ }^{\mathrm{b}}(\mathrm{PhD})$

\author{
(a), (b) Department of Sociology \\ University of Cambridge \\ Free School Lane \\ Cambridge CB2 3RQ \\ United Kingdom
}

Emails: (a)hwm24@cam.ac.uk; (b)mi305@cam.ac.uk

Corresponding author: Hei Wan Mak 


\section{Abstract}

2

3 Background: Several studies have uncovered a relationship between parenting styles and the

4 likelihood that adolescents use tobacco, alcohol or illegal drugs. Objectives: This paper 5 extends existing research in two ways. First, we consider a longer time-frame, investigating the 6 relationship between parenting in adolescence and substance use in adulthood. Second, we 7 explore the pathways by which this relationship is expressed, in particular the extent to which 8 the relationships in question are mediated by age at first use and depression. Methods: Our analysis is based on data from the National Longitudinal Study of Adolescent Health (Add Health), $\mathrm{N}=2954$, and is conducted using structural equation modelling (SEM). We consider warmth and control as distinct dimensions of parenting, as well as a typology of parenting which combines the two dimensions. Results: Warmth is associated with reduced risks of problem substance use in adulthood, via reduced risks of early initiation and a lower risk of depression. Parental control also has a protective effect via reduced risks of early initiation, but this is offset by a detrimental effect on depression, particularly in the case of older adolescents. We also find that indulgent parenting is not associated with extra risk of any kind compared with the authoritative style, whereas authoritarian and neglectful styles are. Conclusions/Importance: The nexus of relationships which we uncover has implications for policy aimed at reducing substance use in the longer term, suggesting that initiatives to promote warm and responsive parenting may be most effective in reducing the risks of later substance use problems.

23 Keywords: Adolescent health; substance use problems; depression; parenting styles; 24 longitudinal analysis. 


\section{Introduction}

The social costs of alcohol, tobacco and illegal drug use are considerable; recent estimates suggest that excessive drinking costs the US almost $\$ 250$ billion each year (Sacks et al., 2015), while smoking-related illness accounts for almost $9 \%$ of healthcare spending (Xu et al., 2015). Substance use also exacts heavy personal costs on the individuals involved and their families, in the form of mental and physical health problems, lost income, relationship problems, and lost years of life (Whiteford et al., 2013; U.S. Department of Health and Human Services (HHS) \& Office of the Surgeon General U.S., 2016) .

There is evidence that parenting and family relationships influence the propensity for substance use in adolescence, and that interventions promoting effective parenting can reduce adolescent substance use (Schinke et al., 2011; Haggerty et al., 2013; Allen et al., 2016). However, there is also evidence that adolescent substance use is extremely widespread (Young et al., 2002), often experimental and self-limiting, and in itself generally not associated with a significant degree of contemporaneous or future harm (Baumrind, 1991; Englund et al., 2013). This is not to say that that adolescent substance use is unproblematic - indeed, it is a significant predictor of later substance use problems (McCambridge et al., 2011) - but given limited resources available for prevention programs, it is arguable that research on substance use should focus on identifying the determinants of problem usage beyond adolescence (Shedler \& Block, 1990).

This paper is based on four waves of data from the Add Health study, a prospective longitudinal survey that follows a group of children $(\mathrm{N}=2954)$ from adolescence into early adulthood. We explore the effects of parenting style in adolescence (when sample members have a mean age of 15.4 years), on problem use of tobacco, alcohol, marijuana and other illegal drugs 13 years later, when sample members have a mean age of 28.2 - by which point most 
people have jobs, many have families, and substance use is no longer a youthful indiscretion but may potentially have serious effects on life chances.

We use a model of parenting styles originating in the work of Baumrind (1966, 1968, 1971, 1991). It proposes two distinct dimensions of parenting: warmth/responsiveness (the degree to which the parent/child relationship is warm, close and affectionate), and control/demandingness (the degree to which parents have expectations of good behavior on the part of their children, and the extent to which they encourage or enforce compliance with those expectations). Baumrind's original schema defined three parenting styles: authoritative (high in both warmth and control); authoritarian (high in control but low in warmth); and permissive (low in control). This schema has formed the basis for widely-used survey instruments (Robinson et al., 1995) and for a large body of research, in areas including developmental competence (Baumrind, 1971, 1991); self-esteem (Buri et al., 1988; Chan \& Koo, 2011); and educational achievement (Dornbusch, 1987; Steinberg et al., 1989); the authoritative parenting style is almost invariably associated with the best outcomes.

This threefold schema has now been largely superseded by a full orthogonal two-factor model, which divides the permissive group into an indulgent group, high in warmth and low in control; and a neglectful group, low in both warmth and control (Maccoby \& Martin, 1983). This schema decouples low- and high-warmth parents among those exerting lower levels of control; many studies using this schema find that indulgent parenting is associated with outcomes as good as authoritative parenting, while outcomes for the neglectful group are poor; in other words, the major effect is via the warmth rather than the control axis. This pattern is found in several studies examining mental or psychological competence and wellbeing (Stafford et al., 2016; García \& Gracia, 2009; Eun et al., 2018; Schofield et al., 2012; Martinez et al., 2017; Martinez et al., 2019). A number of studies relating specifically to substance use in adolescence also find similar results, including those of Kandel et al. (1978), Bronte-Tinkew et al. (2006), Adalbjarnardottir and 
Hafsteinsson (2001), Ozer et al. (2011), Martinez et al. (2013), Calafat et al. (2014), and Valente et al. (2017).

Not all studies find warmth to be the more important dimension. Some studies find both dimensions to be of approximately equal importance, either as determinants of competence and adjustment (Lamborn et al., 1991; Steinberg et al., 1994), or as protective factors against substance use (Hill et al., 2005; Piko \& Balázs, 2012). Other studies suggest that control is more important than warmth as a protective factor against adolescent substance use (Barnes et al., 2000; Kosterman et al., 2000; Aquilino \& Supple, 2001; Choquet et al., 2008).

This paper seeks to extend the state of knowledge in two ways. First, we examine a time frame extending from adolescence into the late twenties. Most studies in this area have focused on adolescence, with longitudinal studies following subjects only into late adolescence or the early adult years (Steinberg et al., 1994; Barnes et al., 2000; Aquilino \& Supple, 2001; Roche et al., 2008; Mogro-Wilson, 2008; Stone et al., 2012, Van Ryzin et al., 2012). Very few studies follow adolescents into adulthood. Dubow et al. (2008) consider a three-item composite of negative family interactions in adolescence, finding it weakly related to drinking behaviour in adulthood. Maggs, Patrick, and Feinstein (2008) find the quality of parent-child relationships at age 16 is associated with alcohol consumption at age 16 and 33, and harmful drinking at age 42. White et al. (2000) find that parental warmth and hostility predict trajectories of smoking behaviour, but predict drinking only weakly. Clark et al. (2015) find that authoritarian parenting is associated with a lower risk of heavy episodic drinking at age 12 across all racial groups.

The second innovation of this study is that, in addition to assessing the effects of parental warmth and control on substance use problems in adulthood, we seek to investigate the pathways via which these effects are played out. We examine two potential pathways, which are suggested by different branches of the literature. 

research on the relationship between parenting style and substance use; several papers in this area (e.g. Garcia \& Gracia, 2009; Velleman et al., 2005) note specifically a link between parenting style and early initiation. We also expect to find a link between early initiation and 103 the risk that an individual will go on to experience substance use problems. The "critical period" hypothesis, which originated in studies of language acquisition, suggests that there is a developmental period in the early teens during which individuals are particularly sensitive to the effects of substance use; those using substances at this age may be at substantially elevated risk of substance use disorder, or substance-related harm, in later life. The studies of Guttmannova (2011) and Maimaris and McCambridge (2014) focus on alcohol misuse, with the former suggesting evidence for a sensitive period and the latter urging more caution; Jordan and Andersen (2017) consider a wider range of substances and find evidence for a sensitive period in adolescence. Several other studies, while not specifically invoking the sensitive period hypothesis, also show that early initiation is related to higher risks of later problems.

113 Anthony and Petronis (1995), Grant and Dawson (1998), McGue et al. (2001), King and

114 Chassin (2007) and Richmond-Rakerd et al. (2017) consider illegal drug use, while DeWit et al. (2000), Grant, Stinson and Harford (2001), Hingson et al. (2006), Dawson et al. (2008) and McCambridge et al. (2011) consider alcohol.

The second pathway we investigate is via depression. As noted above (Stafford et al.,

1182016 and others), parenting style is associated with many aspects of mental health, with parental

119 warmth exerting a protective effect. Poor mental health may in turn increase individuals' susceptibility to substance use problems. The "self-medication" hypothesis suggests that individuals with mental health problems engage in substance use as a way of alleviating their symptoms. The hypothesis was originally formulated in relation to opiate addiction (Khantzian et al., 1974), and has given rise to research on a range of substances (Weiss et al., 1992; Lerman 
et al., 1996, 1998; Bolton et al., 2009). The theory has been critiqued on the grounds that observed associations between mental health problems and substance use may not be causal in the hypothesized direction (Lembke, 2012); however, studies examining the sequencing of onset of mental health problems and substance use suggest that mental health problems are likely to precede substance use disorders (Deykin et al., 1987; Abraham et al., 1999). The selfmedication hypothesis may relate to many mental health problems; we use depressive symptoms, since detailed information on other mental health problems is not collected in the data set we use.

\section{Data and Methods}

Analysis is based on data from the National Longitudinal Study of Adolescent Health (Add Health), a longitudinal study managed from the Carolina Population Center at the University of North Carolina (Harris, 2009).

The survey follows a nationally representative sample of adolescents who were in school grades 7-12 in the 1994/95 school year. Over 90,000 students completed an initial questionnaire in school; a subsample was selected for in-home interview in the same year, with parents also interviewed. Sample members were re-interviewed in 1996, 2001/02 for a third time, and 2008 for a fourth time. At the time of writing, a fifth wave of interviews is under way, but data are not yet available.

Response rates across Waves 1 to 4 are $79 \%, 88.6 \%, 77.4 \%$ and $80.3 \%$ respectively

143 (response rates at Waves 2, 3 and 4 are calculated as percentages of the original Wave 1

144 participants who were eligible for subsequent waves). In a study of attrition from this survey,

145 Brownstein et al. (2010) found that Wave 1 respondents who were male, non-white, non-

146 native-born, or from families with lower levels of education and socioeconomic status were

147 more likely to drop out; however, attrition bias is relatively small after sample weights are 
applied. The results presented are from unweighted regressions (see Winship \& Radbill, 1994;

149 Solon et al., 2015); weighted regressions give similar results.

Our analysis uses the public use data set, which is a randomly generated subsample of

151 the core data set. We restrict the sample to respondents aged between 13 and 18 at the time of

152 first interview (that is, who were of the usual ages for membership of the relevant school grades); these respondents were aged between 25 and 32 at the time of the fourth interview. This gives a core sample size of 2954, which varies slightly between different specifications. Table 1 provides descriptive statistics for the variables of interest; other descriptive statistics may be found in the Appendix.

\section{(Table 1)}

\subsection{Outcome variables: substance use problems in adulthood}

Outcomes are measured in Wave 4. The instruments for problem use of alcohol, marijuana and other drugs are based on the criteria for the diagnosis of Substance Use Disorder in the Diagnostic and Statistical Manual of Mental Disorders, fourth edition (DSIM-IV); these have been extensively validated (Van Dulmen et al., 2002; Hasin et al., 2006). The problem drinking scale is derived from 10 items $(\alpha=0.88)$; the scales for problem marijuana use $(\alpha=0.85)$ and problem use of other drugs $(\alpha=0.92)$ are each based on 8 items. These scales are standardized (mean=0, SD=1). Lists of items used to derive these and other latent scales are provided in the Appendix. The smoking indicator represents average daily cigarette consumption, derived from two questions: the number of days on which respondents smoked over the past month, and the average number of cigarettes smoked on each of these days. The smoking scale is top-coded at 20 and is unstandardized (mean=3.12, $\mathrm{SD}=6.12$ ). As well as these continuous measures, we also generate binary variables indicating the 5\% of heaviest smokers, and individuals scoring the highest $5 \%$ on the substance problem scales. 
In certain situations, the use of multiple outcome measures may give rise to problems

with statistical inference; the larger the number of outcomes, the more likely that a significant result will be found for at least one of them (Shaffer, 1995). One solution involves adjusting confidence intervals. We do not do this, since the same relationships between parenting style and later substance use are observed in relation to every outcome.

\subsection{Parenting style}

Parenting style is measured in Add Health via bespoke survey instruments which draw on several existing well-validated instruments (Udry, 2001); we use data collected at Wave 1. We generate two scales, as follows. The warmth scale reflects maternal responsiveness, emotional bonding, and trust. It is based on 12 items, some of which were reported by adolescents and some by mothers $(\alpha=0.75)$. The control scale is derived from 7 items $(\alpha=0.62)$. The measure we use is a reversed scale of the degree to which parents grant autonomy; in Section 3.1 we explore alternative conceptualisations of control, namely monitoring and demandingness. All questions relating to these scales are asked of both mothers and fathers. We use responses from mothers; the same analysis using responses from fathers gives similar results, but sample sizes are smaller.

Existing literature shows consistently that parenting styles vary according to adolescent age and gender (Belsky, 1984; Parent et al., 2014). We are primarily interested in the effects of parenting styles inasmuch as they are typical or atypical for adolescents at a particular stage in life; we therefore adjust the relevant scales for age and sex. The scales are then standardized.

We also derive an indicator of parenting style based on the fourfold schema described in the Introduction. We define a categorical variable denoting four parenting styles: authoritative (a score above the median for both warmth and control); indulgent (scores above the median in warmth and below the median in control); authoritarian (below the median in warmth and above the median in control); and neglectful (below the median in both warmth and control). 


\subsection{Mediators}

We use several specifications for the age at first use of each substance (for drinking, marijuana and other illegal drugs, this is the age at which the substance was ever used; for smoking, it indicates the age at which the respondent first smoked regularly). Our main model is based on a binary indicator of whether first use had occurred by Wave 1. We also present models based on (a) initiation by Wave 2, for those who had not used the substance by Wave 1; (b) a continuous indicator of age at first use, derived from responses to all four waves of the survey; and (c) a binary variable indicating initiation by age 16 .

Depressive symptoms are measured in the Add Health survey by a modified version of the Center for Epidemiologic Studies Depression Scale (CES-D), an instrument in wide use which has been validated for adolescents and young adults (Roberts et al., 1990; Radloff, 1991). This measure is available in each of the four waves; we use the measure at Wave 3 as a mediator, since it post-dates the measurement of parenting styles and precedes the measurement of the outcome. The scale is based on 12 items $(\alpha=0.82)$, and is standardized, with higher scores denoting more depressed individuals.

\subsection{Control variables}

We control for the following variables at Wave 1: age, gender, ethnicity, parental education (in two-parent families, the higher), family composition, peers' substance use (Jackson et al., 1997; von Sydow et al., 2002), and maternal substance use (Baumrind, 1991; Bailey et al., 2016); we include maternal drinking in the alcohol use regressions and maternal smoking in all other regressions. Parental employment and neighborhood safety were found to be insignificant and were not included in the model.

We control for several variables measured at Wave 4: completed years of education, religiosity (a standardized scale based on 5 items, $\alpha=0.83$ ), employment; marital status; and whether the individual has children. 


\subsection{Methods}

Our analysis is based on structural equation modelling (SEM) in Stata 13. SEM treats

224

225

226

all relationships in the model as linear; Hellevik (2009) shows that the inclusion of dichotomous mediators (here, initiation by Wave 1) does not cause problems in this context. One of our robustness checks uses a dichotomous outcome; this is estimated with generalized structural equation modelling (GSEM), described by Rabe-Hesketh et al. (2004).

We specify a system of relationships which allows parenting behavior to exercise a direct effect on the outcome variables, as well as indirect effects via initiation and depression. Of the two mediators, initiation is measured prior to depression; we therefore allow initiation to influence depression. Controls measured at Wave 1 may influence both mediators and outcomes; controls measured at Wave 4 influence only outcomes.

Four models were estimated, one relating to problem usage of each of the four substances considered. Full results are available in the Appendix; Tables 2 and 3 in the body of the paper, which present results from the two-dimension and fourfold models of parenting respectively, contain only the coefficients on the parenting style variables and the mediating pathways.

Tables 2 and 3 also contain test statistics for the significance of the mediation pathways; these are from the Sobel procedure (Sobel, 1982), which tests whether the estimated effects of the parenting variables on the outcome variables are significantly attenuated by the inclusion of the mediators. We performed two alternative tests, the Aroian and Goodman tests (MacKinnon et al., 2002); these are not reported but the results are similar.

\section{Results}

Figure 1 presents estimates from a model estimating the determinants of marijuana problems at Wave 4. This is based on the two-dimensional model of parenting style. Of the two dimensions, only warmth has a direct effect on the outcome. Both mediators (first use by Wave 
2471 and depression at Wave 3) are positively and significantly associated with marijuana

248 problems at Wave 4. Parental warmth has a significant negative association with both

249 mediators. Parental control is negatively associated with initiation, but is positively related to

250 depression at Wave 3. These results suggest that warm parenting is related to a lower risk of

251 problem marijuana use in adulthood, by three pathways: (1) directly; (2) via a lower risk of early initiation; and (3) via lower risks of depression. It also suggests that a parenting style high in control has (1) no significant direct effect on the outcome, (2) a beneficial effect via a lowered risk of early initiation; and (3) a negative effect via a higher risk of depression. We return later to a fuller discussion of these findings.

(Figure 1)

Table 2 presents results from the same model, for all four outcomes. The top panel contains estimates of the effects of parenting styles on the outcome variables: direct effects (the effects attributable to all parts of the model except the mediators); indirect effects (effects via the mediating pathways) and total effects (the sum of these). There are significant direct effects from warmth for all outcomes except smoking, and significant indirect effects from warmth for all outcomes. There are no significant effects, direct or indirect, from control.

The second panel shows mediation effects. Both mediators are significantly related to all outcome variables, except that depression at W3 is not significantly related to smoking. Warmth is associated with lower risks of initiation and with lower risks of depression. Control is associated with lower risks of initiation (for drinking and marijuana), but with higher risks of depression (in all except the smoking model). 

pathways are significant mediators of the effect of parental warmth (except depression in the smoking regression). The evidence is less compelling in relation to the effects of parental control. Initiation is a significant mediator of parental control only in the drinking equation (although in the other three equations, the test statistic is in the same direction, and is associated with a $p$-value of $p<0.1)$. Similarly, depression is a significant mediator of parental control only in the marijuana problems equation; however, the test statistic is of the same sign in all the other three equations, and associated with a $p$-value of $p<0.1$ in two of them).

Results for all models demonstrate good model fit (Bartholomew et al., 2008 define a good fit as a value $<0.05$ for RMSEA, a value close to 1 for CFI, and a value $<0.08$ for SRMR).

Table 3 presents results from models using the fourfold typology of parenting described above; the baseline group is the 'authoritative' style. Results again demonstrate good model fit (Bartholomew et al., 2008). Few direct effects of parenting style are evident, but strong indirect effects are observed for the authoritarian and neglectful types, yielding significant total effects for all outcomes except smoking. Hardly any difference is evident between the indulgent and authoritative styles.

\section{(Table 3)}

There is compelling evidence that both mediation pathways are significant. For all outcomes, both the authoritarian and neglectful parenting types are associated with (a) a higher risk of initiation by Wave 1; and (b) a higher risk of depression at Wave 3. The Sobel test statistics show that initiation is a significant mediator of the relationship between the authoritarian and neglectful parenting styles and all four outcomes; depression is a significant mediator for all outcomes except smoking. 


\subsection{Robustness checks}

297

We estimated several alternative specifications as robustness checks; results are presented in Table 4. As an initial check (not shown), we tested for nonlinearities and interactions in the effects of parental warmth and control. We found no evidence that any of the estimated relationships were significantly nonlinear, and no interaction effects beyond what is evident in the fourfold typology.

Panel 1 of Table 4 shows results from a model based on binary outcomes identifying the $5 \%$ of heaviest smokers and the $5 \%$ of highest scores on the alcohol and drug problem scales. The fact that this specification yields results similar to our previous results indicates that our model successfully predicts severe substance use problems as well as variations across the full range.

Panel 2 addresses the implicit assumption that adolescents' substance use is influenced by parenting, rather than parenting responding to substance use; it is plausible that effects could run in the opposite direction. We analyze the sample of adolescents who had not initiated substance use by Wave 1, with initiation by Wave 2 as a measure of first use. Parenting at Wave 1 predicts initiation by Wave 1 more strongly than initiation by Wave 2; this may indicate a degree of bidirectional causality, or simply that in the former case, parenting style is a more proximal measure. In any case, the fact that significant relationships remain in the second specification indicates that at least part of the estimated relationship operates in the assumed direction.

We then restrict the sample to those who have initiated substance use by Wave 4 . Results (not reported) are substantially unchanged; this suggests that that parenting style affects 
not just the probability of initiation, but also the propensity to develop problems following initiation.

We next explore alternative specifications for the indicator of initiation. Panel 3 reports results using a continuous measure of age at initiation (individuals who had never used the substance by Wave 4 are excluded). Results are once again similar: warmth is related to older age at initiation and negatively related to depression, while control is also related to older age at initiation, albeit with smaller coefficients than warmth.

In panels 4 and 5, we use a binary variable indicating whether initiation occurred by age 16. This has the advantage of being a common benchmark for all sample members, but the disadvantage that initiation and parenting are measured at different times. For those aged over 16 at Wave 1, parenting is measured after initiation has (or has not) occurred; for those under 16, parenting is measured before the cut-off point for measuring initiation. We therefore analyze 13-15-year olds and 17-18-year-olds separately. Effects differ substantially between the two age groups, with the main differences being in the determinants of depression. The effect of warmth on depression is about twice as large for the younger group as for the older group; the effect of control on depression is insignificant for the younger group, but large and significant for the older group. This suggests that parental warmth is important for all adolescents, but particularly so at younger ages, while the relationship between control and depression is most pronounced at older ages. We also investigated whether there are differences by gender: greater parental control is associated with depression at Wave 3 for both sexes, but the effect is larger in the case of boys. Our final robustness checks explore alternative specifications for the control dimension.

343 Our original variable indicates the control which parents exercise over several domains of their 344 children's lives. However, some other studies have used alternative concepts: monitoring 345 (knowing/controlling children's whereabouts), or a wider concept of "demandingness", which 
involves expectations of maturity good behavior, and a degree of enforcement of these standards (Baumrind, 1991). Replacing the indicator of control with an indicator of monitoring based on whether adolescents are allowed to make their own decisions about (a) who they associate with, and (b) what time they come home on weekends yields coefficients of the same sign but reduced magnitude (Panel 6); the effect of monitoring on initiation becomes tiny and insignificant, while its relationship with depression is positive, but significant only at the $10 \%$ level. We also test an indicator of demandingness which includes adolescents' frequency of participation in housework. This was not included in our original indicator of control because it reduced the fit of the model. The housework indicator is negatively (albeit insignificantly) related to depression (Panel 7), suggesting that, to the extent that the control/demandingness dimension is negatively related to depression, this is driven by parental control. Results (not shown) using a composite indicator of demandingness which also includes housework are similar to our initial results.

\section{Discussion}

Prior research has demonstrated that parenting style is associated with the risk of substance use in late adolescence and/or early adulthood (e.g. Steinberg et al., 1994; Barnes et al., 2000; Aquilino \& Supple, 2001; Stone et al., 2012). This paper shows that these effects persist into the longer term: warm parenting protects against problem substance use when subjects are well into adulthood. In addition, we have highlighted two pathways via which this effect can be shown to work: the age at initiation of substance use, and depression.

We used two specifications for parenting style: one which includes continuous measures of warmth and control, and a fourfold typology based on those two dimensions. In each case, the results are unequivocal: it is parental warmth, and not control, which protects against substance use problems in adulthood. In the fourfold typology, it is the authoritarian 
and neglectful styles which are associated with elevated risks of later substance use; the indulgent style is not associated with extra risks of any kind.

Our analysis of mediating pathways may shed light on heterogeneity between prior studies. Virtually all studies show that warm parenting is protective, and we show the same. However, some studies (Aquilino \& Supple, 2001, and others) have found parental control to be protective against substance use in adolescence, while others (Calafat et al., 2014 and others) have not. We have found that parental control does inhibit the initiation of substance use in adolescence (see Tables 2 and 4), but that this protective effect does not persist into adulthood; we suggest this may be due to a link between controlling parenting and depression. Thus, the effects of parental control may differ according to the age at which the outcome is measured, and may account for the range of findings in different studies.

Our study has several strengths. It is based on a nationally representative sample, with a considerably longer follow-up period than is typically used in studies in this area; its findings make a novel and useful contribution to the state of knowledge. However, our study is not without its limitations. First, our measures of substance use initiation and of parenting style were collected contemporaneously. While it is reasonable to believe that parenting affects substance use, it is also likely that parenting style is itself influenced by adolescents' prior substance use. We have addressed this problem partially in the robustness checks, but we believe there is more scope for disentangling issues of timing and directionality in this relationship. We also believe there is scope for a better understanding of the control/demandingness dimension; our robustness checks suggest that an alternative definition based on adolescents' contributions at home may yield interesting results, but data including an expanded survey instrument would be needed to test this. Finally, there is evidence that individuals self-medicate for a range of mental health conditions, notably for anxiety, which is 
an extremely common condition (Robinson et al, 2009) but the data allowed us to test only for a pathway via depression.

\section{Conclusions and implications for policy}

There is already evidence that interventions promoting effective parenting may reduce

398 substance use in adolescence (Haggerty et al., 2013). One justification for interventions in 399 adolescence is that teenage substance use predicts problems in adulthood; our results confirm this, 400 and thus indicate that parenting initiatives may be protective in the longer as well as the shorter 401 term.

However, our finding that over the longer term warmth is of much greater importance 403 than control may have important implications for the formulation of future parenting 404 interventions. This would be true even if substance problems in adulthood were the only outcome of concern; however, if mental health is considered as locus of concern in its own right, rather than solely as a forerunner of substance use problems, the relative importance of a parenting style high in warmth assumes an even higher importance.

\section{Declaration of Interest}

The authors report no conflicts of interest. 
Figure 1: The relationship between parenting in adolescence and marijuana problems in Wave 4; path diagram showing results from SEM analysis.

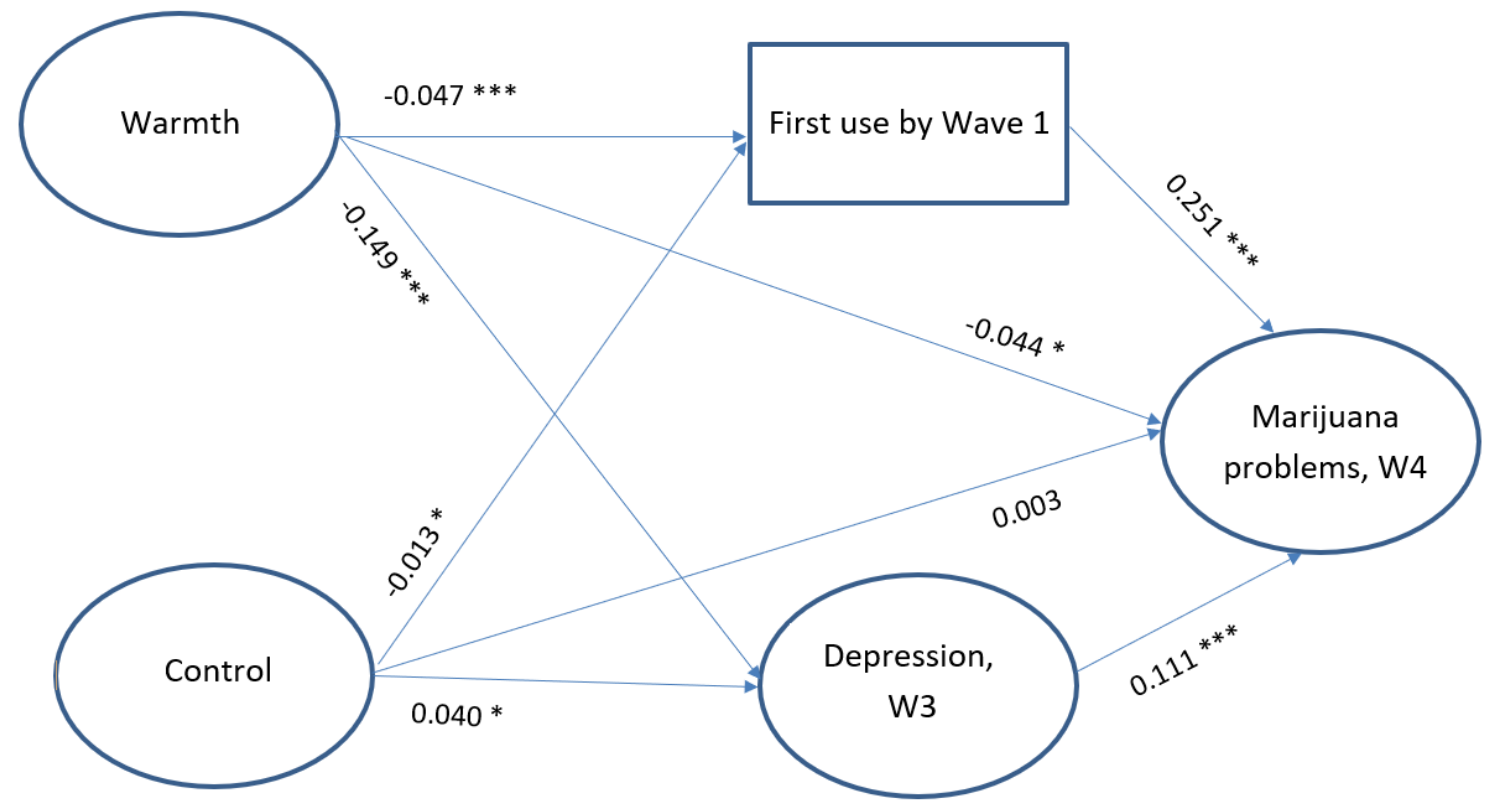

Note: For clarity, some relationships have been omitted from the diagram. These are: (1) the determinants of the latent constructs that are not directly observed, such as the parenting dimensions and mental health problems; (2) control variables; (3) the relationship between first use and mental health problems. Standard errors in parentheses. Statistical significance is denoted by asterisks: * sig at 5\%, ** sig at 1\%, *** sig at 0.1. 
Table 1 Descriptive Statistics: outcome variables, parenting style variables and mediators

\begin{tabular}{|c|c|c|c|}
\hline \multirow{2}{*}{ Variable } & \multicolumn{2}{|c|}{ Range of Values } & \multirow{2}{*}{$\begin{array}{c}\text { Mean (SD) } \\
\text { or } \%\end{array}$} \\
\hline & Min & Max & \\
\hline \multicolumn{4}{|l|}{ Outcome Variables, W4 } \\
\hline Ave. number of cigarettes per day in past 30 days & 0 & 20 or more & $3.12(6.11)$ \\
\hline Drinking problems & -0.61 & 3.58 & $0.01(0.99)$ \\
\hline Marijuana problems & -0.39 & 5.52 & $0.00(1.00)$ \\
\hline Other illicit drug problems & -0.27 & 5.92 & $-0.01(0.98)$ \\
\hline \multicolumn{4}{|l|}{ Variables of Interest } \\
\hline \multicolumn{4}{|l|}{ Parenting styles in dimensions } \\
\hline Warmth, W1 & -4.50 & 2.30 & $-0.01(1.02)$ \\
\hline Control, W1 & -1.96 & 4.00 & $-0.01(0.97)$ \\
\hline \multicolumn{4}{|l|}{ Fourfold schema of parenting styles, W1 } \\
\hline Authoritative (Ref) & 0 & 1 & 24.6 \\
\hline Indulgent & 0 & 1 & 25.1 \\
\hline Authoritarian & 0 & 1 & 25.4 \\
\hline Neglectful & 0 & 1 & 25.0 \\
\hline \multicolumn{4}{|l|}{ Mediators } \\
\hline Cigarette use by W1 & 0 & 1 & $0.19(0.39)$ \\
\hline Alcohol use by W1 & 0 & 1 & $0.45(0.50)$ \\
\hline Marijuana use by W1 & 0 & 1 & $0.24(0.43)$ \\
\hline Illegal drug use by W1 & 0 & 1 & $0.27(0.44)$ \\
\hline Age first smoked regularly (years) & 10 or younger & 30 & $16.4(3.31)$ \\
\hline Age first used alcohol (years) & 10 or younger & 30 & $16.2(3.13)$ \\
\hline Age first used marijuana (years) & 10 or younger & 29 & $16.7(3.02)$ \\
\hline Age first used illegal drug (years) & 10 or younger & 31 & $18.3(4.25)$ \\
\hline Mental health problems, W3 & -1.35 & 4.92 & $-0.03(0.96)$ \\
\hline
\end{tabular}


Table 2: Relationships between parenting style in adolescence and substance use problems in adulthood; two dimensions of parenting style, coefficients from SEM analysis ( $N=2954)$

\begin{tabular}{|c|c|c|c|c|c|c|}
\hline & & & $\begin{array}{l}\text { Smoking } \\
\text { (cigs/day) }\end{array}$ & $\begin{array}{l}\text { Drinking } \\
\text { problems }\end{array}$ & $\begin{array}{l}\text { Marijuana } \\
\text { problems }\end{array}$ & $\begin{array}{l}\text { Other illicit drug } \\
\text { problems }\end{array}$ \\
\hline \multirow{6}{*}{$\begin{array}{l}\text { Effects of parenting } \\
\text { style on Wave } 4 \\
\text { outcomes }\end{array}$} & \multirow{2}{*}{ Direct effects } & Warmth & $0.016(0.101)$ & $-0.038(0.017)^{*}$ & $-0.044(0.018)^{*}$ & $-0.046(0.018)^{\star *}$ \\
\hline & & Control & $0.037(0.104)$ & $-0.014(0.018)$ & $0.003(0.019)$ & $0.006(0.018)$ \\
\hline & \multirow{2}{*}{ Indirect effects } & Warmth & $-0.201(0.031)^{\star * *}$ & $-0.023(0.004)^{\star \star \star}$ & $-0.029(0.005)^{\star \star \star}$ & $-0.024(0.004)^{\star * *}$ \\
\hline & & Control & $-0.031(0.024)$ & $-0.005(0.003)$ ↔ & $0.001(0.003)$ & $-0.001(0.002)$ \\
\hline & \multirow{2}{*}{ Total effects } & Warmth & $-0.180(0.101)$ ઐ & $-0.060(0.017)^{* * *}$ & $-0.071(0.018)^{* * *}$ & $-0.069(0.018)^{\star * *}$ \\
\hline & & Control & $0.002(0.106)$ & $-0.019(0.018)$ & $0.004(0.019)$ & $-0.008(0.018)$ \\
\hline \multirow{6}{*}{ Mediation effects } & \multirow{3}{*}{$\begin{array}{l}\text { Via initiation } \\
\text { by Wave } 1\end{array}$} & Warmth $\rightarrow$ initiation & $-0.048(0.006)^{* * *}$ & $-0.052(0.008)^{* * *}$ & $-0.047(0.006)^{* * *}$ & $-0.054(0.007)^{\star * *}$ \\
\hline & & Control $\rightarrow$ initiation & $-0.010(0.006)$ & $-0.025(0.008)^{\star *}$ & $-0.013(0.007)^{*}$ & $-0.014(0.007) \rightsquigarrow$ \\
\hline & & Initiation $\rightarrow$ outcome & $3.614(0.303)^{\star \star *}$ & $0.295(0.042)^{\star \star *}$ & $0.251(0.052)^{* * *}$ & $0.263(0.048)^{* * *}$ \\
\hline & \multirow{3}{*}{$\begin{array}{l}\text { Via depression } \\
\text { at Wave } 3\end{array}$} & Warmth $\rightarrow$ depression & $-0.146(0.017)^{* * *}$ & $-0.156(0.017)^{* * \star}$ & $-0.149(0.017)^{* \star *}$ & $-0.145(0.017)^{* * *}$ \\
\hline & & Control $\rightarrow$ depression & $0.040(0.018)^{*}$ & $0.039(0.018)^{*}$ & $0.040(0.018)^{*}$ & $0.041(0.018)^{\star}$ \\
\hline & & Depression $\rightarrow$ outcome & $0.175(0.108)$ & $0.051(0.019)^{* *}$ & $0.111(0.019)^{\star * *}$ & $0.068(0.019)^{* * *}$ \\
\hline \multirow{4}{*}{$\begin{array}{l}\text { Sobel test statistics } \\
\text { for significance of } \\
\text { mediating pathways }\end{array}$} & \multirow{2}{*}{ Initiation } & Warmth & $-6.644^{* * *}$ & $-4.771^{* * *}$ & $-4.109^{* * *}$ & $-4.467^{* * *}$ \\
\hline & & Control & -1.651 ๘ & $-2.855^{\star *}$ & -1.733 ॠ & $-1.879 \rightsquigarrow$ \\
\hline & \multirow{2}{*}{ Depression } & Warmth & -1.592 & $-2.576^{* *}$ & $-4.861^{* * *}$ & $-3.300^{* * *}$ \\
\hline & & Control & 1.335 & $1.686 \rightsquigarrow$ & $2.077^{*}$ & $1.922 \rightsquigarrow$ \\
\hline \multirow{4}{*}{ Statistics of fit } & & RMSEA & 0.040 & 0.041 & 0.040 & 0.040 \\
\hline & & SRMR & 0.008 & 0.008 & 0.008 & 0.008 \\
\hline & & $C F I$ & 0.964 & 0.957 & 0.960 & 0.957 \\
\hline & & $C D$ & 0.434 & 0.437 & 0.443 & 0.409 \\
\hline
\end{tabular}

Standard errors in parentheses.

Statistical significance is denoted by asterisks: ${ }^{*}$ sig at $5 \%,{ }^{* *}$ sig at $1 \%,{ }^{* * *}$ sig at $0.1 \%$. Insignificant results with $p<0.1$ denoted by $\overbrace{}^{\natural}$.

Post-estimation tests on differences between parental warmth and parental control:

Direct effects: Other illicit drugs *; Indirect effects: all substances ${ }^{* * *}$; Total effects: marijuana ${ }^{* *}$ other illicit drugs *

Effects on initiation: all substances ${ }^{* *}$ or better. Effects on depression: all substances ${ }^{* * *}$ 
Table 3: Relationships between parenting style in adolescence and substance use problems in adulthood; fourfold typology of parenting style, coefficients from SEM analysis ( $N=2954)$

\begin{tabular}{|c|c|c|c|c|c|c|}
\hline & & & $\begin{array}{l}\text { Smoking } \\
\text { (cigs/day) }\end{array}$ & $\begin{array}{l}\text { Drinking } \\
\text { problems }\end{array}$ & $\begin{array}{l}\text { Marijuana } \\
\text { problems }\end{array}$ & $\begin{array}{l}\text { Other illicit drug } \\
\text { problems }\end{array}$ \\
\hline \multirow{9}{*}{$\begin{array}{l}\text { Effects of parenting } \\
\text { style on Wave } 4 \\
\text { outcomes }\end{array}$} & \multirow{3}{*}{ Direct effects } & Indulgent & $-0.001(0.283)$ & $0.017(0.049)$ & $0.006(0.051)$ & $0.006(0.050)$ \\
\hline & & Authoritarian & $0.158(0.284)$ & $0.062(0.049)$ & $0.049(0.051)$ & $0.079(0.050)$ \\
\hline & & Neglectful & $0.002(0.287)$ & $0.115(0.050)^{*}$ & $0.079(0.051)$ & $0.072(0.051)$ \\
\hline & & Indulgent & $0.055(0.064)$ & $0.020(0.008)^{*}$ & $-0.008(0.008)$ & $-0.003(0.007)$ \\
\hline & Indirect effects & \multirow{2}{*}{$\begin{array}{l}\text { Authoritarian } \\
\text { Neglectful }\end{array}$} & $0.261(0.070)^{\star * *}$ & $0.045(0.009)^{\star * *}$ & $0.039(0.009)^{* * *}$ & $0.031(0.008)^{\star \star \star}$ \\
\hline & & & $0.295(0.069)^{* * *}$ & $0.048(0.009)^{\star * *}$ & $0.039(0.009)^{* * *}$ & $0.037(0.008)^{* * *}$ \\
\hline & & Indulgent & $0.056(0.289)$ & $0.036(0.049)$ & $-0.001(0.051)$ & $0.003(0.050)$ \\
\hline & Total effects & Authoritarian & $0.407(0.289)$ & $0.105(0.049)^{*}$ & $0.085(0.051)$ ఔ & $0.108(0.050)^{*}$ \\
\hline & & Neglectful & $0.292(0.292)$ & $0.160(0.050)^{\star \star}$ & $0.117(0.052)^{*}$ & $0.108(0.051)^{\star}$ \\
\hline \multirow{8}{*}{ Mediation effects } & \multirow{4}{*}{$\begin{array}{l}\text { Via initiation } \\
\text { by Wave } 1\end{array}$} & Indulgent $\rightarrow$ initiation & $0.019(0.017)$ & $0.082(0.022)^{\star * *}$ & $0.008(0.018)$ & $0.011(0.019)$ \\
\hline & & Authoritarian $\rightarrow$ initiation & $0.061(0.017)^{\star * *}$ & $0.110(0.021)^{\star * *}$ & $0.047(0.018)^{* *}$ & $0.054(0.019)^{\star *}$ \\
\hline & & Neglectful $\rightarrow$ initiation & $0.075(0.017)^{\star * \star}$ & $0.134(0.022)^{\star \star \star}$ & $0.087(0.018)^{\star \star \star}$ & $0.098(0.019)^{* * *}$ \\
\hline & & $\rightarrow$ outcome & $3.599(0.302)^{\star * *}$ & $0.297(0.042)^{\star * *}$ & $0.264(0.052)^{* * *}$ & $0.271(0.048)^{* * *}$ \\
\hline & \multirow{4}{*}{$\begin{array}{l}\text { Via depression } \\
\text { at Wave } 3\end{array}$} & Indulgent $\rightarrow$ depression & $-0.083(0.049) \hookleftarrow$ & $-0.086(0.049) \hookleftarrow$ & $-0.089(0.049) \hookleftarrow$ & $-0.090(0.049) \hookleftarrow$ \\
\hline & & Authoritarian $\rightarrow$ depression & $0.229(0.049)^{\star * \star}$ & $0.240(0.049)^{\star \star \star}$ & $0.230(0.049)^{\star \star \star}$ & $0.227(0.049)^{\star * \star}$ \\
\hline & & Neglectful $\rightarrow$ depression & $0.140(0.049)^{* *}$ & $0.157(0.050)^{\star *}$ & $0.141(0.049)^{\star *}$ & $0.134(0.049)^{* *}$ \\
\hline & & Depression $\rightarrow$ outcome & $0.167(0.107)$ & $0.053(0.018)^{\star *}$ & $0.114(0.019)^{\star * \star}$ & $0.070(0.019)^{\star * \star}$ \\
\hline \multirow{6}{*}{$\begin{array}{l}\text { Sobel test statistics } \\
\text { for significance of } \\
\text { mediating pathways }\end{array}$} & \multirow{3}{*}{ Initiation } & Indulgent & 1.113 & $3.297^{* * *}$ & 0.443 & 0.576 \\
\hline & & Authoritarian & $3.436^{\star * *}$ & $4.209^{\star \star \star}$ & $2.322^{*}$ & $2.539^{*}$ \\
\hline & & Neglectful & $4.137^{* \star *}$ & $4.615^{\star \star \star}$ & $3.501^{* * *}$ & $3.808^{* * *}$ \\
\hline & \multirow{3}{*}{ Depression } & Indulgent & -1.148 & -1.508 & -1.738 ↔ & -1.644 \\
\hline & & Authoritarian & 1.480 & $2.524^{*}$ & $3.697^{\star * *}$ & $2.884^{\star *}$ \\
\hline & & Neglectful & 1.370 & $2.148^{*}$ & $2.595^{\star *}$ & $2.196^{*}$ \\
\hline \multirow{4}{*}{ Statistics of fit } & & RMSEA & 0.041 & 0.043 & 0.042 & 0.041 \\
\hline & & $S R M R$ & 0.008 & 0.009 & 0.008 & 0.008 \\
\hline & & $C F I$ & 0.961 & 0.952 & 0.955 & 0.951 \\
\hline & & $C D$ & 0.421 & 0.428 & 0.431 & 0.396 \\
\hline
\end{tabular}

Standard errors in parentheses.

Statistical significance is denoted by asterisks: * sig at $5 \%,{ }^{* *}$ sig at $1 \%$, ${ }^{* *}$ sig at $0.1 \%$. Insignificant results with $p<0.1$ denoted by ${ }^{\sharp}$.

Post-estimation tests on differences between indulgent, authoritarian and neglectful parenting styles:

Direct effects: None sig; Indirect effects: Indulgent $v$ authoritarian and indulgent $v$ neglectful, all substances * or better; Total effects: none sig

Effects on initiation: Indulgent $v$ neglectful, all except drinking, ${ }^{* *}$ or better; other comparisons $n / s$; 


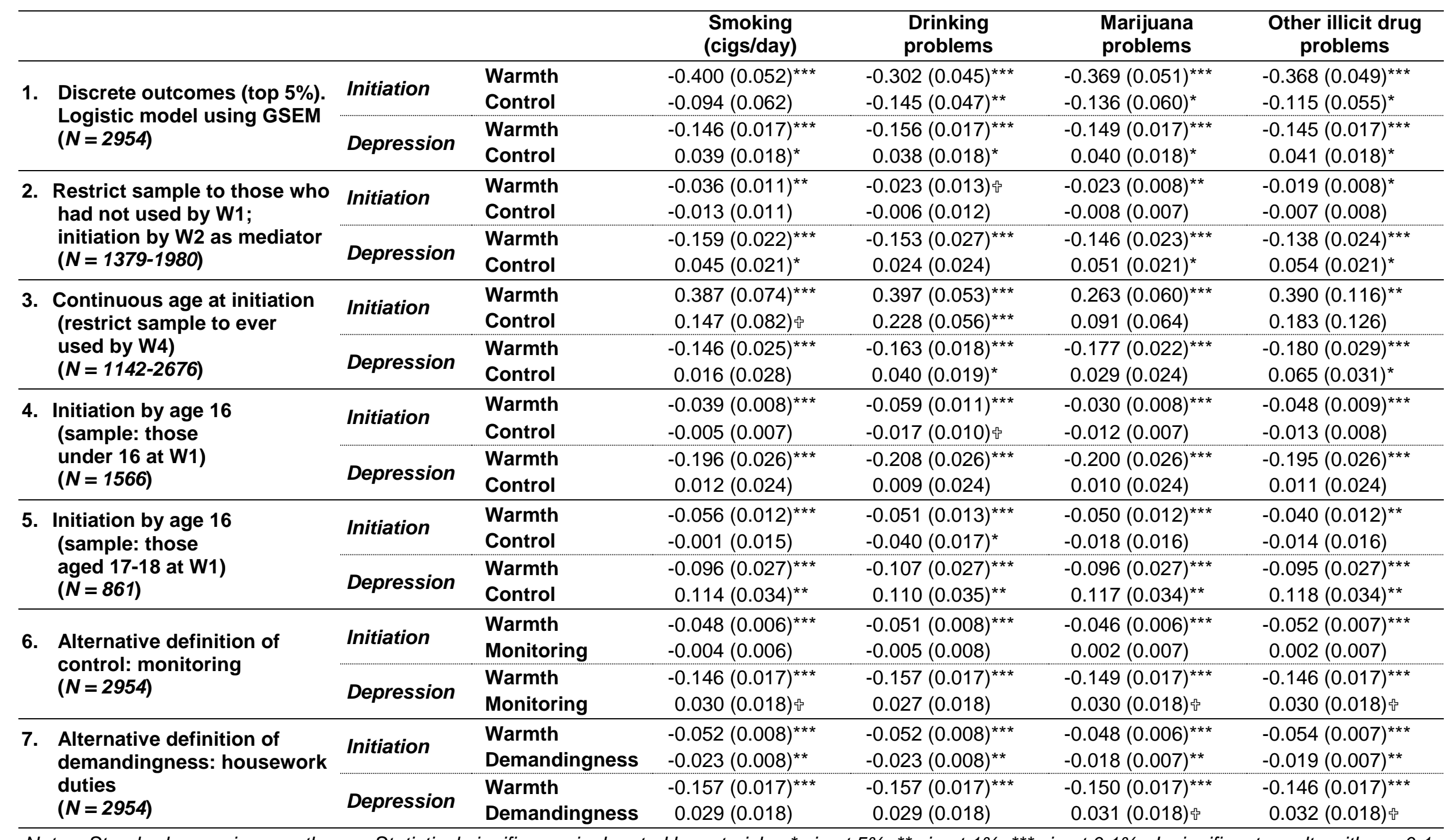

Notes: Standard errors in parentheses. Statistical significance is denoted by asterisks: ${ }^{*}$ sig at $5 \%,{ }^{* *}$ sig at $1 \%,{ }^{* * *}$ sig at $0.1 \%$. Insignificant results with $p<0.1$ denoted by i? $^{3}$. 


\section{References}

Abraham, H.D., \& Fava, M. (1999). Order of onset of substance abuse and depression in a sample of depressed outpatients. Comprehensive Psychiatry, 40(1), 44-50.

Adalbjarnardottir, S., \& Hafsteinsson, L.G. (2001). Adolescents' perceived parenting styles and their substance use: Concurrent and longitudinal analyses. Journal of Research on Adolescence, 11(4), 401-423.

Allen, M.L., Garcia-Huidobro, D., Porta, C., Curran, D., Patel, R., Miller, J., \& Borowsky, I. (2016). Effective parenting interventions to reduce youth substance use: A systematic review. Pediatrics, e20154425.

Anthony, J.C., \& Petronis, K.R. (1995). Early-onset drug use and risk of later drug problems. Drug and alcohol dependence, 40(1), 9-15.

Aquilino, W., \& Supple, A. (2001). Long-term effects of parenting practices during adolescence on well-being outcomes in young adulthood. Journal of Family Issues, 22(3), 289-308.

Bailey, J., Hill, K.G., Guttmannova, K., Epstein, M., Abbott, R.D., Steeger, C.M., \& Skinner, M.L. (2016). Associations between parental and grandparental marijuana use and chid substance use norms in a prospective, three-generation study. Journal of Adolescent Health, 59(3), 262-268.

Barnes, G.M., Reifman, A.S., Farrell, M.P., \& Dintcheff, B.A. (2000). The effects of parenting on the development of adolescent alcohol misuse : a six-wave latent growth model. Journal of Marriage and the Famiily, 62, 175-186.

Bartholomew, D.J., Steele, F., Galbraith, J., \& Moustaki, I. (2008). Analysis of multivariate social sceicne data, second edition. Chapman \& Hall/CRC, Boca Raton, FL.

Baumrind, D. (1966). Effects of authoritative parental control on child behavior. Child development, 37(4), 887-907.

Baumrind, D. (1968). Authoritarian vs. authoritative parental control. Adolescence, 3(11), 255-272.

Baumrind, D. (1971). Developmental psychology monograph current patterns of parental authority. Developmental Psychology Monograph, 4(1), 1-103.

Baumrind, D. (1991). The influence of parenting style on adolescent competence and substance use. Journal of Early Adolescence, 11(1), 56-95.

Belsky, J. (1984). The determinants of parenting: A process model. Child Development, 55(1), 83-96.

Bolton, J.M., Robinson, J., \& Sareen, J. (2009). Self-medication of mood disorders with alcohol and drugs in the National Epidemiologic Survey on Alcohol and Related Conditions. Journal of affective disorders, 115(3), 367-375.

Bronte-Tinkew, J., Moore, K.A., \& Carrano, J. (2006). The father-child relationship, parenting styles, and adolescent risk behaviors in intact families. Journal of family issues, 27(6), 850-881.

Brownstein, N., Kalsbeek, W.D., Tabor, J., Entzel, P., Daza, E., \& Mullan Harris, K.M. (2010). Non-response in Wave IV of the National Longitudinal Study of Adolescent Health. Retrieved from http:// www.cpc.unc.edu/projects/addhealth/data/guides/W4_nonresponse.pdf

Buri, J.R., Louiselle, P.A., Misukanis, T.M., \& Mueller, R.A. (1988). Effects of parental authoritarianism and authoritativeness on self-esteem. Personality and Social Psychology Bulletin, 14(2), 271282.

Calafat, A., García, F., Juan, M., Becoña, E., \& Fernández-Hermida, J.R. (2014). Which parenting style is more protective against adolescent substance use? Evidence within the European context. Drug and Alcohol Dependence, 138(1), 185-192.

Chan, T.W., \& Koo, A. (2011). Parenting style and youth outcomes in the UK. European sociological review, 27(3), 385-399.

Choquet, M., Hassler, C., Morin, D., Falissard, B., \& Chau, N. (2008). Perceived parenting styles and tobacco, alcohol and cannabis use among French adolescents: Gender and family structure differentials. Alcohol \& Alcoholism, 43(1), 73-80.

Clark, T.T., Yang, C., McClernon, F.J., \& Fuemmeler, B.F. (2015). Racial differences in parenting style typologies and heavy episodic drinking trajectories. Health Psychology, 34, 697-708.

Dawson, D.A., Goldstein, R.B., Patricia Chou, S., June Ruan, W., \& Grant, B.F. (2008). Age at first drink and the first incidence of adult-onset DSM-IV alcohol use disorders. Alcoholism: Clinical and Experimental Research, 32(12), 2149-2160. 
DeWit, D.J., Adlaf, E.M., Offord, D.R., \& Ogborne, A.C. (2000). Age at first alcohol use: A risk factor for the development of alcohol disorders. The American Journal of Psychiatry, 157(5), 745-750.

Deykin, E.Y., Levy, J.C., \& Wells, V. (1987). Adolescent depression, alcohol and drug abuse. American Journal of Public Health, 77(2), 178-182.

Dornbusch, S.M., Ritter, P.L., Leiderman, P.H., Roberts, D.F., \& Fraleigh, M.J. (1987). The relation of parenting style to adolescent school performance. Child development, 1244-1257.

Dubow, E.F., Boxer, P., \& Huesmann, L.R. (2008). Childhood and adolescent predictors of early and middle adulthood alcohol use and problem drinking: The Columbia County Longitudinal Study. Addiction, 103(SUPPL. 1), 36-47.

Englund, M., Siebenbruner, J., Oliva, E., Egeland, B., Chung, C.T., \& Long, J. (2013). The developmental significance of late adolescent substance use for early adult functioning. Developmental psychology, 49(8), 1554-1564.

Eun, J.D., Paksarian, D., He, J.P., \& Merikangas, K.R. (2018). Parenting style and mental disorders in a nationally representative sample of US adolescents. Social psychiatry and psychiatric epidemiology, 53(1), 11-20.

Garcia, F., \& Gracia, E. (2009). Is always authoritative the optimum parenting style? Evidence from Spanish families. Adolescence, 44(173), 101-131.

Grant, B.F., \& Dawson, D.A. (1998). Age of onset of drug use and its association with DSM-IV drug abuse and dependence: Results from the National Longitudinal Alcohol Epidemiologic Survey. Journal of substance abuse, 10(2), 163-173.

Grant, B.F., Stinson, F.S., \& Harford, T.C. (2001). Age at onset of alcohol use and DSM-IV alcohol abuse and dependence: A 12-year follow-up. Journal of substance abuse, 13(4), 493-504.

Guttmannova, K., Bailey, J.A., Hill, K.G., Lee, J.O., Hawkins, J.D., Woods, M.L., \& Catalano, R.F. (2011). Sensitive periods for adolescent alcohol use initiation: Predicting the lifetime occurrence and chronicity of alcohol problems in adulthood. Journal of studies on alcohol and drugs, 72(2), 221-231.

Haggerty, K., McGlynn-Wright, A., \& Klima, T. (2013). Promsing parenting programs for reducing adolecent problem behaviors. Journal of Children's Services, 8(4), 1-15.

Harris, K.M. (2009). The National Longitudinal Study of Adolescent to Adult Health (Add Health), Waves I \& II, 1994-1996; Wave III, 2001-2002; Wave IV, 2007-2009 [machine-readable data file and documentation]. Chapel Hill, NC: Carolina Population Center, University of North Carolina at Chapel Hill.

Hasin, D., Hatzenbuehler, M.L., Keyes, K., \& Ogburn, E. (2006). Substance use disorders: Diagnostic and Statistical Manual of Mental Disorders, (DSM-IV) and International Classification of Diseases, (ICD-10). Addiction, 101, 59-75.

Hellevik, O. (2009). Linear versus logistic regression when the dependent variable is a dichotomy. Quality and Quantity, 43(1), 59-74.

Hill, K.G., Hawkins, J.D., Catalano, R.F., Abbott, R.D., \& Guo, J. (2005). Family influences on the risk of daily smoking initiation. Journal of Adolescent Health, 37(3), 202-210.

Hingson, R.W., Heeren, T., \& Winter, M.R. (2006). Age at drinking onset and alcohol dependence. Archives of Pediatrics \& Adolescent Medicine, 160(7), 739.

Jackson, C., Dickinson, D., \& Levine, D.W. (1997). The early use of alcohol and tobacco: Its relation to children's competence and parents' behavior. American Jounral of Public Health, 87(3), 359364.

Jordan, C.J., \& Andersen, S.L. (2017). Sensitive periods of substance abuse: Early risk for the transition to dependence. Developmental cognitive neuroscience, 25, 29-44.

Kandel, D.B., Kessler, R.C., \& Margulies, R.Z. (1978). Antecedents of adolescent initiation into stages of drug use: A developmental analysis. Journal of Youth and Adolescence, 7(1), 13-40.

Khantzian, E.J., Mack, J.E., \& Schatzberg, A.F. (1974). Heroin use as an attempt to cope: Clinical observations. American Journal of Psychiatry, 131(2), 160-164.

King, K.M., \& Chassin, L. (2007). A prospective study of the effects of age of initiation of alcohol and drug use on young adult substance dependence*. Journal of Studies on Alcohol and Drugs, 68(2), 256-265.

Kosterman, R., Hawkins, J.D., Guo, J., Catalano, R.F., \& Abbott, R.D. (2000). The dynamics of alchol and 
marijuana initiation: Patters and predictors of first use in adolescence. American Journal of Public Health, 90(3), 360-366.

Lamborn, S.D., Mounts, N.S., Steinberg, L., \& Dornbusch, S.M. (1991). Patterns of competence and adjustment among adolescents from authoritative, authoritarian, indulgent, and neglectful families. Child development, 62(5), 1049-1065.

Lembke, A. (2012). Time to abandon the self-medication hypothesis in patients with psychiatric disorders. The American Journal of Drug and Alcohol Abuse, 38(6), 524-529.

Lerman, C., Audrain, J., Orleans, C.T., Boyd, R., Gold, K., Main, D., \& Caporaso, N. (1996). Investigation of mechanisms linking depressed mood to nicotine dependence. Addictive behaviors, 21(1), 9-19.

Lerman, C., Caporaso, N., Main, D., Audrain, J., Boyd, N.R., Bowman, E.D., \& Shields, P.G. (1998). Depression and self-medication with nicotine: the modifying influence of the dopamine D4 receptor gene. Health Psychology, 17(1), 56-62.

Maccoby, E.E. \& Martin, J.A. (1983) Socialization in the context of the family: Parent-child interaction. In: Mussen PH, ed. Handbook of Child Psychology: Formerly Carmichael's Manual of Child Psychology.

MacKinnon, D.P., Lockwood, C.M., Hoffman, J.M., West, S.G., \& Sheets, V. (2002). A comparison of methods to test mediation and other intervening variable effects. Psychological Methods, 7, 83-104.

Maggs, J.L., Patrick, M.E., \& Feinstein, L. (2008). Childhood and adolescent predictors of alcohol use and problems in adolescence and adulthood in the National Child Development Study. Addiction, 103(SUPPL. 1), 7-22.

Maimaris, W., \& McCambridge, J. (2014). Age of first drinking and adult alcohol problems: systematic review of prospective cohort studies. Journal of Epidemiology and Community Health, 68(3), 268-274.

Martínez, I., Fuentes, M.C., García, F., \& Madrid, I. (2013). El estilo de socialización familiar como factor de prevención o riesgo para el consumo de sustancias y otros problemas de conducta en los adolescentes españoles. Adicciones, 25(3), 235-242.

Martínez, I., Cruise, E., García, Ó.F., \& Murgui, S. (2017). English validation of the parental socialization scale-ESPA29. Frontiers in Psychology, 8, 865.

Martínez, I., Murgui, S., Garcia, O. F., \& Garcia, F. (2019). Parenting in the digital era: protective and risk parenting styles for traditional bullying and cyberbullying victimization. Computers in Human Behavior, 90, 84-92.

McCambridge, J., McAlaney, J., \& Rowe, R. (2011). Adult consequences of late adolescent alcohol consumption: a systematic review of cohort studies. PLoS medicine, 8(2), e1000413.

McGue, M., Iacono, W.G., Legrand, L.N., Malone, S., \& Elkins, I. (2001). Origins and consequences of age at first drink. I. Associations with substance-use disorders, disinhibitory behavior and psychopathology, and P3 amplitude. Alcoholism: Clinical and Experimental Research, 25(8), 1156-1165.

Mogro-Wilson, C. (2008). The influence of parental warmth and control on Latino adolescent alcohol use. Hispanic Journal of Behavioral Sciences, 30(1), 89-105.

Ozer, E.J., Flores, E., Tschann, J.M., \& Pasch, L.A. (2011). Parenting style, depressive symptoms, and substance use in mexican american adolescents. Youth \& Society, 45(3), 365-388.

Parent, J., Forehand, R., Dunbar, J.P., Watson, K.H., Reising, M.M., Seehuus, M., \& Compas, B.E. (2014). Parent and adolescent reports of parenting when a parent has a history of depression: associations with observations of parenting. Journal of Abnormal Child Psychology, 42(2), 173-183.

Piko, B.F., \& Balázs, M.Á. (2012). Authoritative parenting style and adolescent smoking and drinking. Addictive Behaviors, 37(3), 353-356.

Rabe-Hesketh, S., Skrondal, A., \& Pickles, A. (2004) Generalized multilevel structural equation modeling. Psychometrika, 69(2), 167-190.

Radloff, L.S. (1991). The use of the Center for Epidemiologic Studies Depression Scale in adolescents and young adults. Journal of youth and adolescence, 20(2), 149-166. 
Richmond-Rakerd, L.S., Slutske, W.S., \& Wood, P.K. (2017). Age of initiation and substance use progression: A multivariate latent growth analysis. Psychology of Addictive Behaviors, 31(6), 664.

Roberts, R.E., Andrews, J.A., Lewinsohn, P.M., \& Hops, H. (1990). Assessment of depression in adolescents using the Center for Epidemiologic Studies Depression Scale. Psychological Assessment: A Journal of Consulting and Clinical Psychology, 2(2), 122.

Robinson, C.C., Mandleco, B., Olsen, S.F., \& Hart, C.H. (1995). Authoritative, authoritarian, and permissive parenting practices: Development of a new measure. Psychological reports, 77(3), 819-830.

Robinson, J., Sareen, J., Cox, B.J., \& Bolton, J. (2009). Self-medication of anxiety disorders with alcohol and drugs: Results from a nationally representative sample. Journal of anxiety disorders, 23(1), 38-45.

Roche, K.M., Ahmed, S., \& Blum, R.W. (2008). Enduring consequences of parenting for risk behaviors from adolescence into early adulthood. Social Science and Medicine, 66(9), 2023-2034.

Sacks, J.J., Gonzales, K.R., Bouchery, E.E., Tomedi, L.E., \& Brewer, R.D. (2015). 2010 National and state costs of excessive alcohol consumption. American Journal of Preventive Medicine, 49(5), e73e79.

Schinke, S.P., Fang, L., Cole, K.C., \& Cohen-Cutler, S. (2011). Preventing substance use among Black and Hispanic adolescent girls: Results from a computer-delivered, mother-daughter intervention approach. Substance use \& misuse, 46(1), 35-45.

Schofield, T.J., Conger, R.D., Donnellan, M.B., Jochem, R., Widaman, K.F., \& Conger, K.J. (2012). Parent personality and positive parenting as predictors of positive adolescent personality development over time. Merrill-Palmer quarterly (Wayne State University. Press), 58(2), 255283.

Shaffer, J.P. (1995) Multiple hypothesis testing. Annual review of psychology, 46, 561-584.

Shedler, J., \& Block, J. (1990). Adolescent drug use and psychological health. A longitudinal inquiry. The American Psychologist, 45(5), 612-630.

Sobel, M.E. (1982). Asymptotic intervals for indirect effects in structural equations models. In S. Leinhart (Ed.), Sociological methodology 1982 (pp.290-312). San Francisco: Jossey-Bass.

Solon, G., Haider, S.J., \& Wooldridge, J. (2015). What are we weighting for? Journal of Human Resources, 50(2), 301-316.

Stafford, M., Kuh, D.L., Gale, C.R., Mishra, G., \& Richards, M. (2016). Parent-child relationships and offspring's positive mental wellbeing from adolescence to early older age. The journal of positive psychology, 11(3), 326-337.

Steinberg, L., Elmen, J.D., \& Mounts, N.S. (1989). Authoritative parenting, psychosocial maturity, and academic success among adolescents. Child development, 60(6), 1424-1436.

Steinberg, L., Lamborn, S.D., Darling, N., Mounts, N.S., Dornbusch, S.M., Steinberg, L., \& Darling, N. (1994). Over-time changes in adjustment and competence among adolescents from authoritative, authoritarian, indulgent, and neglectful families. Child Development, 65(3), 754-770.

Stone, A.L., Becker, L.G., Huber, A.M., \& Catalano, R.F. (2012). Review of risk and protective factors of substance use and problem use in emerging adulthood. Addictive Behaviors, 37(7), 747-775.

Udry, J.R. (2001). References, Instruments, and Questionnaires Consulted in the Development of the Add Health In-home Adolescent Interview. Briefing paper on Add Health Survey Instruments, University of North Carolina at Chapel Hill. http://www.cpc.unc.edu/projects/addhealth/documentation/guides/refer.pdf

U.S. Department of Health and Human Services (HHS) \& Office of the Surgeon General U.S. (2016). Facing Addiction in America: The Surgeon General's Report on Alcohol, Drugs, and Health. In: U.S. Department of Health and Human Services (HHS), ed: Washington, DC: HHS; 2016. Retrieved from https://addiction.surgeongeneral.gov/surgeon-generals-report.pdf

Valente, J.Y., Cogo-Moreira, H., \& Sanchez, Z.M. (2017). Gradient of association between parenting styles and patterns of drug use in adolescence: A latent class analysis. Drug and Alcohol Dependence, 180, 272-278.

Van Ryzin, M., Fosco, G., \& Dishion, T. (2012). Family and peer predictors of substance use from early 
adoelscence to early adulthood: An 11-year prospective anlayis. Addictive Behaviors, 37(12), 1314-1324.

van Dulmen, M.H., Grotevant, H.D., Dunbar, N., Miller, B.C., Bayley, B., Christensen, M., \& Fan, X. (2002). Connecting national survey data with DSM-IV criteria. Journal of Adolescent Health, 31(6), 475-481.

Velleman, R.D., Templeton, L.J., \& Copello, A.G. (2005). The role of the family in preventing and intervening with substance use and misuse: A comprehensive review of family interventions, with a focus on young people. Drug and alcohol review, 24(2), 93-109.

von Sydow, K., Lieb, R., Pfister, H., Hofler, M., \& Wittchen, H. (2002). What predicts incident use of cannabis and progression to abuse and dependence ? A 4-year prospective examination of risk factors in a community sample of adolescents and young adults. Drug \& Alcohol Dependence, 68(1), 49-64.

Weiss, R.D., Griffin, M.L., \& Mirin, S.M. (1992). Drug abuse as self-medication for depression: An empirical study. The American journal of drug and alcohol abuse, 18(2), 121-129.

White, H.R., Johnson, V., \& Buyske, S. (2000). Parental modeling and parenting behavior effects on offspring alcohol and cigarette use. A growth curve analysis. Journal of Substance Abuse, 12(3), 287-310.

Whiteford H.A., et al. (2013) Global burden of disease attributable to mental and substance use disorders: Findings from the Global Burden of Disease Study 2010. The Lancet, 382, 15751586.

Winship, C., \& Radbill, L. (1994). Sampling weights and regression analysis. Sociological Methods \& Research, 23(2), 230-257.

Xu, X., Bishop, E., Kennedy, S., Simpson, S., \& Pechacek, T. (2015). Annual healthcare spending attributable to cigarette smoking: An update. American Jounral of Preventive Medicine, 48(3), 95-121.

Young, S.E., Corley, R.P., Stallings, M.C., Rhee, S.H., Crowley, T.., \& Hewitt, J.K. (2002). Substance use, abuse and dependence in adolescence: prevalence, symptom profiles and correlates. Drug and alcohol dependence, 68(3), 309-322. 